Recepción: 23 / 06 / 2017

Aceptación: 12 / 07 / 2017

Publicación: 01 / 09 / 2017
Ciencias sociales y políticas

Artículo de investigación

\title{
El procedimiento directo en el ordenamiento jurídico penal Ecuatoriano
}

The direct procedure in the Ecuadorian criminal legal system

O procedimento direto no sistema jurídico criminal Equatoriano

\author{
Mauro Alfredo Pinargoty-Alonzo \\ alpin-juez@hotmail.es \\ Jaime M. Marín-Rodríguez ${ }^{\text {II }}$ \\ jaime-marin10@hotmail.com
}

Correspondencia: alpin-juez@hotmail.es

I. Magíster en Derecho Penal Y Criminología, Diploma Superior en Derechos Fundamentales, Doctor en Jurisprudencia, Especialista en Sistemas Jurídicos de Protección a los Derechos Humanos, Abogado de los Juzgados I Tribunales de la República, Diploma Superior en Derecho Procesal Penal, Especialista Superior en Derecho Procesal, Docente de la Universidad Laica Eloy Alfaro de Manabí, Manta, Ecuador.

II. Magíster en Comercio Exterior con Mención en Gestión Tributaria Aduanera, Especialista en Diseño Curricular por Competencias, Abogado de los Juzgados I Tribunales de la República, Docente de la Universidad Laica Eloy Alfaro de Manabí, Manta, Ecuador. 


\title{
Resumen
}

El trabajo está enfocado en analizar el procedimiento directo en el ordenamiento jurídico penal ecuatoriano. Con este fin se realiza una investigación bibliográfica, científico jurídica. En virtud de lo expuesto se procede a examinar la doctrina, esencialmente en lo que respecta a las garantías constitucionales y el Código Orgánico Integral Penal en relación con el procedimiento directo. Concluyendo que el procedimiento directo es una forma de recabar la justicia de una manera oportuna en un tiempo mucho más rápido y en la cual los operadores de justicia deben aplicar su mayor esfuerzo por obtener un resultado eficaz al momento de dictar una sentencia. De igual forma, el principio de celeridad procesal no debe afectar el principio de defensa, ni tampoco debe dejar a la parte acusadora en este caso para probar un hecho sin el tiempo, los medios necesarios para descubrir y plantear algo muy parecido a la reconstrucción de un hecho, en el que se vaya a sancionar a una persona por un ilícito y reparar los daños de la víctima.

Palabras clave: Procedimiento directo; Ordenamiento jurídico; Celeridad procesal.

\begin{abstract}
The work is focused on analyzing the direct procedure in the Ecuadorian criminal legal system. To this end, a bibliographical, legal scientific research is carried out. In view of the foregoing, the doctrine is examined, essentially as regards the constitutional guarantees and the Organic Comprehensive Criminal Code in relation to the direct procedure. Concluding that the direct procedure is a way to collect justice in a timely manner in a much faster time and in which the justice operators must apply their best effort to obtain an effective result at the time of issuing a sentence. Similarly, the principle of procedural speed must not affect the principle of defense, nor should it leave the accusing party in this case to prove an event without time, the necessary means to discover and raise something very similar to the reconstruction of a fact, in which a person will be sanctioned for an illegal act and repair the victim's damages.
\end{abstract}

Key words: Direct procedure; legal order; procedural speed. 


\section{Resumo}

O trabalho está focado na análise do processo direto no sistema jurídico criminal equatoriano. Para isso, é realizada uma pesquisa bibliográfica, cientista jurídica. Com base no exposto, a doutrina é examinada, essencialmente no que diz respeito às garantias constitucionais e ao Código Penal Orgânico Integral em relação ao procedimento direto. Concluindo que o procedimento direto é uma maneira de obter a justiça em tempo hábil, em um tempo muito mais rápido e em que os operadores da justiça devem aplicar seus melhores esforços para obter um resultado efetivo no momento da emissão de uma sentença. Da mesma forma, o princípio da velocidade processual não deve afetar o princípio da defesa, nem deve deixar a parte acusadora, neste caso, provar um fato sem tempo, os meios necessários para descobrir e propor algo muito semelhante à reconstrução do processo. um fato, no qual uma pessoa será punida por um ato ilícito e reparará os danos da vítima.

Palavras-chave: Procedimento direto; Ordem jurídica; Velocidade processual.

\section{Introducción}

A partir del nacimiento del Código Orgánico Integral Penal (COIP) el 10 de Agosto del 2014, en el país entraron en vigencia nuevas ideas y así mismo procedimientos "especiales", como un sistema alternativo de justicia que busca la solución eficaz y eficiente a los problemas cotidianos (según las opiniones vertidas por los asambleístas), dentro de estos llamados procedimientos especiales es posible encontrar el Procedimiento Directo, el cual va a ser el enfoque principal para el desarrollo de este trabajo.

Siendo importante resaltar que el procedimiento Directo se creó bajo un nuevo modelo de Gestión de Justicia, el cual sin duda, hasta la actualidad, ha sido objeto de grandes expectativas y debates por parte de quienes interpretan la ley y por ende de todas aquellas personas que hacen posible su ejecución; puesto que este procedimiento tiene como fin concentrar todas las etapas penales en una sola audiencia.

En este sentido se hace énfasis en que el Procedimiento directo nace de una flagrancia debidamente calificada como tal, su aplicación solo cabe en delitos que contengan una sanción de pena privativa de libertad que no exceda de 5 años, así mismo determina su aplicación a los delitos contra la 
propiedad, pero sólo siempre y cuando el monto no exceda de 30 salarios básicos unificados del trabajador en general.

Por ello, en su aplicación quedan excluidas las infracciones contra la administración pública o que afecten a los intereses del Estado, delitos contra la inviolabilidad de la vida, integridad y libertad personal con resultado muerte, delitos contra la integridad sexual, reproductiva y delitos de violencia contra la mujer o miembros del núcleo familiar.

De igual forma, la competencia para sustanciar y resolver el Procedimiento Directo es exclusiva de la Jueza o el Juez de Garantías Penales perteneciente a una Unidad Judicial (flagrancia/turno), quien de manera unipersonal es quien va a tramitar y sentenciar este tipo de procedimiento, caso contrario a lo normalmente visto, esto es, ser juzgados y sentenciados por un tribunal de garantías penales, tal como lo determina el Art. 529 del Código Orgánico Integral Penal (audiencia de flagrancia).

Con relación a lo expuesto, la Jueza o Juez, una vez que califica la audiencia de flagrancia, convoca a los sujetos procesales dentro de diez días contados a partir de la sustanciación de la antes mencionada audiencia para que se lleve a efecto la Audiencia de Juicio Directo, en la cual se dictará sentencia.

Por ello, la creación de un Procedimiento Especial en la legislación Ecuatoriana "Procedimiento Directo" ha sido de vital importancia, porque de ser una ventaja como lo estipula la ley, ayudaría a dar una solución eficaz a problemas que nacen a partir del cometimiento de un delito, puesto que por tratarse de un procedimiento que está consagrado a la celeridad procesal permite que se resuelva conflictos más rápido que en el Sistema Penal anterior.

Considerando que en diez días este procedimiento puede hacer que un procesado sea sentenciado o por el contrario se desvirtúen todos los indicios estimados para llevar a esa persona a una prisión preventiva de ser el caso, en este sentido, los 10 días se cuentan a partir de la audiencia de Flagrancia donde se acogió este procedimiento directo, las partes procesales tanto como Fiscalía General del Estado y por su parte la Defensa deberán recurrir a la práctica de varias diligencias para el esclarecimiento del delito, presentando de manera objetiva pruebas de cargo y descargo que permitan demostrar la materialidad de la infracción, la responsabilidad penal y por otra parte desvirtuar todo indicio de que la persona procesada cometió un delito, por ende librarla de toda clase de responsabilidad penal que recaiga sobre ella. 
En correspondencia a lo planteado anteriormente, con la adecuación de este tipo de procedimiento a la legislación del país, surtieron una serie de debates por parte de quienes lo aplican, ya que sin lugar a duda con la aplicación de este procedimiento también surgen ventajas o desventajas que algunas veces pueden favorecer a la Fiscalía como a la defensa.

Dentro de las ventajas se puede considerar que el proceso llevado a efecto por el cometimiento de un delito va a ser más eficaz, se tendrá una sentencia en un tiempo mucho más rápido; para la defensa es ventajoso esta situación ya que por tratarse de pocos días para efectuarse el Juicio de Procedimiento Directo, tiene tiempo preciso pero contundente a los efectos de presentar pruebas de descargo que eximan de algún tipo de responsabilidad penal a la persona; en cuanto a la Fiscalía como Institución que trabaja con el objeto de presentar pruebas tanto de cargo como de descargo, es un poco más complejo determinar responsabilidad penal con base a un delito flagrante.

De lo planteado se evidencia la necesidad de analizar el procedimiento directo en el ordenamiento jurídico penal ecuatoriano. En tal sentido, se realiza a partir de la norma legal que fundamenta su accionar.

\section{Desarrollo}

\section{Infracción Penal}

El Código Orgánico Integral Penal, determina que: "Es la conducta típica, antijurídica y culpable cuya sanción se encuentra prevista en este Código". (Artículo 18)

Al respecto, quien adecue su conducta a un tipo penal que se encuentra tipificado en la ley, lesione un bien jurídico y sea sancionable con una pena, se debe acoger a un proceso en el cual se determinaría su culpabilidad mediante sentencia. Para lo cual requiere contar con los medios y el tiempo adecuado para ejecutar su defensa.

\section{Procedimiento Ordinario para el Juzgamiento de personas en conflicto con la Ley}

Tal como lo determina el artículo 195 de la Constitución de la República del Ecuador (CRE), la Fiscalía es quien ejercerá de oficio o a petición de parte el ejercicio de la acción penal procesal y pre procesal, según sea el caso. 
Así mismo el artículo 411, determina que "La Fiscalía, ejercerá la acción penal pública cuando tenga los elementos de convicción suficientes sobre la existencia de la infracción y de la responsabilidad de la persona procesada" (COIP, 2014).

En Ecuador con la entrada de vigencia del Código Orgánico Integral Penal, en el mes de Agosto de 2014, al momento de cometerse una infracción Penal, se da inicio a un proceso el cual se subdivide de dos maneras:

\section{Infracciones no Flagrantes:}

Inician cuando se tiene conocimiento del cometimiento de un hecho ilícito, el cual se encuentra sancionado por la ley penal, y que al momento de que la fiscalía avoca conocimiento, da inicio a una fase pre procesal denominada Investigación Previa.

Es así que COIP establece que:

Artículo 580. En la fase de investigación previa se reunirán los elementos de convicción, de cargo y de descargo, que permitan a la o al fiscal decidir si formula o no la imputación y de hacerlo, posibilitará al investigado preparar su defensa.

\section{Infracciones Flagrantes:}

Artículo 527. Se entiende que se encuentra en situación de flagrancia, la persona que comete el delito en presencia de una o más personas o cuando se la descubre inmediatamente después de su supuesta comisión, siempre que exista una persecución ininterrumpida desde el momento de la supuesta comisión hasta la aprehensión, asimismo cuando se encuentre con armas, instrumentos, el producto del ilícito, huellas o documentos relativos a la infracción recién cometida. No se podrá alegar persecución ininterrumpida si han transcurrido más de veinticuatro horas entre la comisión de la infracción y la aprehensión (COIP, 2014) 


\section{El código orgánico integral penal y el trámite ordinario para los delitos flagrantes y no flagrantes}

El Código Orgánico Integral Penal, determina ciertas reglas para el trámite de una instrucción fiscal, según sea el caso. Todo expresado en los siguientes artículos, en sus partes esenciales según corresponde a plazos y extensiones de ellos:

\section{La duración de la instrucción fiscal.}

Artículo 592: En la audiencia de formulación de cargos la o el fiscal determinará el tiempo de duración de la instrucción, misma que no podrá exceder del plazo máximo de noventa días. De existir los méritos suficientes, la o el fiscal podrá declarar concluida la instrucción antes del vencimiento del plazo fijado en la audiencia.

Son excepciones a este plazo las siguientes:

2. En todo delito flagrante la instrucción durará hasta treinta días.

3. En los procedimientos directos.

4. Cuando exista vinculación a la instrucción.

No tendrá valor alguno las diligencias practicadas después de los plazos previstos (COIP, 2014)

Hace una clara referencia a que en los procedimientos directos, varia el tiempo de plazo de investigación procesal, ya que el tiempo determinado para este tipo de procedimiento es de diez días, y las diligencias practicadas después de los plazos previstos no tendrán valor alguno. 
Sobre la vinculación a la instrucción Fiscal, establece:

Artículo 593. Si hasta antes del vencimiento del plazo de la instrucción fiscal, aparecen datos de los que se presume la autoría o la participación de una o varias personas en el hecho objeto de la instrucción, la o el fiscal solicitará su vinculación a la instrucción. La audiencia que se realizará de acuerdo con las reglas generales, se llevará a cabo en un plazo no mayor a cinco días, con la participación directa de la persona o las personas a vincular o con la o el defensor público o privado. Realizada la o las vinculaciones, el plazo de la instrucción se ampliará en treinta días improrrogables.

Esto significa que si dentro de la investigación que realiza la fiscalía en aplicación del Onus Probandi, (carga de la prueba), se encuentra nuevos indicios que hagan presumir que además de la persona procesada, existen otras personas que tengan relación con el hecho, se podrá extender la investigación por treinta días más para poder recabar el total de la información de esta persona.

Adicionalmente, existe la figura de Reformulación de cargos, establecida en el artículo 596 del COIP, en la cual si dentro de la investigación los resultados de la misma hace que varíe el tipo penal por el que se imputó a la persona procesada, esta mediante audiencia se puede extender por treinta días más, esto con el fin de que la persona pueda realizar su defensa con base al nuevo delito imputado.

Es así que una investigación tiene plazos para poder ser tramitada de una forma en la que tanto la Fiscalía y la defensa puedan recabar elementos necesarios a fin de que al momento de llegar un posible juzgamiento, puedan ser utilizados como medios afines a la defensa o imputación de un delito a una persona, sin jugar con su estado de vulnerabilidad ante los organismos de justicia, y el aparataje institucional que recae sobre él.

\section{Procedimientos especiales}

Dentro del Código Orgánico Integral Penal también se encuentran procedimientos especiales, los cuales sirven para la tramitación de causas de forma más rápida, aplicando la celeridad principalmente para la persona que se encuentra en calidad de sospechoso o procesada dentro de una investigación.

El artículo 634 del COIP establece que estos procedimientos especiales son: El procedimiento abreviado, el procedimiento directo, el procedimiento expedito y procedimientos para el ejercicio privado de la acción penal. 
Haciendo una breve referencia a los demás procedimientos sin incluir el que es materia de este trabajo, En este sentido, el Código establece reglas básicas para poder determinar si son aplicables a ciertos tipos de delitos.

El procedimiento abreviado estipulado en el artículo 635 de mencionado cuerpo legal, tiene como referencia las siguientes características referenciales:

- Infracciones con pena máxima de 10 años (el Código de Procedimiento Penal anterior establecía 5 años)

- La propuesta de aplicación de este procedimiento deberá presentarse desde la formulación de cargos hasta la audiencia preparatoria de juicio.

- La persona procesada debe de estar de acuerdo con la aplicación de este procedimiento. (aceptar la responsabilidad)

- En la audiencia si el juzgador no encuentra los requisitos para la aplicación, lo rechazará y ordenará que el fiscal siga sustanciando en trámite ordinario.

De igual forma, el procedimiento expedito estipulado en el artículo 641 del COIP, tiene como referencia lo siguiente:

- Es aplicable para las contravenciones penales y de tránsito.

- Todo se realiza en una sola audiencia.

- Si corresponde la victima con el denunciado llegarán a una conciliación, excepto en violencia intrafamiliar

- Con este acuerdo se pone fin al proceso

- Hasta tres días antes de la audiencia se presentan las pruebas por escrito

- Si es aprehendida la persona mientras es sorprendida en el cometimientos de la contravención las pruebas se anuncian en la misma audiencia.

- Son susceptibles para procedimiento expedito todas las contravenciones de tránsito flagrantes y no flagrantes.

Dentro del procedimiento para el ejercicio privado de la acción penal se estipula en el artículo 647 del COIP lo siguiente:

- Se propone querella por si o mediante apoderado ante el juez de garantías penales.

- Se debe de reconocer la querella 
- No se ordenaran medidas cautelares

- Se concluye por medio del abandono, desistiendo, remisión

- Si no se logra la conciliación se continúa con la audiencia.

- Se entiende abandonada la acusación si el querellante deja de impulsarla por treinta días.

\section{Procedimiento directo}

Es un tipo de procedimiento en el cual se intenta hacer que los procesos penales tengan una celeridad jurídica, pero, qué tan sólido puede ser esta propuesta realizada en el nuevo régimen legislativo existente en el país.

"El llamado procedimiento directo tiene las características de concentrar todas las etapas de una audiencia" (ALFONSO, 2013)

Esto aplicando el principio de celeridad y de economía procesal, en razón de que es posible sustanciar en una sola audiencia todas las audiencias en las que se puede hacer referencia al procedimiento ordinario. A fin de que se evacuen todas las diligencias en una sola.

\section{Formalidades y reglas de la aplicación del procedimiento directo}

El artículo 640 del Código Orgánico Integral Penal determina las reglas para la sustanciación del procedimiento directo:

1. Este procedimiento concentra todas las etapas del proceso en una sola audiencia, la cual se regirá con las reglas generales previstas en este Código.

2. Procederá en los delitos calificados como flagrantes sancionados con pena máxima privativa de libertad de hasta cinco años y los delitos contra la propiedad cuyo monto no exceda de treinta salarios básicos unificados del trabajador en general, calificados como flagrantes.

Se excluirán de este procedimiento las infracciones contra la eficiente administración pública o que afecten a los intereses del Estado, delitos contra la inviolabilidad de la vida, integridad y libertad personal con resultado de 
muerte, delitos contra la integridad sexual y reproductiva y delitos de violencia contra la mujer o miembros del núcleo familiar.

3. La o el juez de garantías penales será competente para sustanciar y resolver este procedimiento.

4. Una vez calificada la flagrancia, la o el juzgador señalará día y hora para realizar la audiencia de juicio directo en el plazo máximo de diez días, en la cual dictará sentencia.

5. Hasta tres días antes de la audiencia, las partes realizarán el anuncio de pruebas por escrito.

6. De considerar necesario de forma motivada de oficio o a petición de parte la o el juzgador podrá suspender el curso de la audiencia por una sola vez, indicando el día y hora para su continuación, que no podrá exceder de quince días a partir de la fecha de su inicio.

7. En caso de no asistir la persona procesada a la audiencia, la o el juzgador podrá disponer su detención con el único fin de que comparezca exclusivamente a ella. Si no se puede ejecutar la detención se procederá conforme a las reglas de este Código.

8. La sentencia dictada en esta audiencia de acuerdo con las reglas de este Código, es de condena o ratificatoria de inocencia y podrá ser apelada ante la Corte Provincial. (COIP, 2014)

Haciendo un desglose del presente artículo se evidencia lo siguiente:

- Se realizará una sola audiencia en la que se concentran la práctica y evacuación de todas las diligencias de cargo y descargo.

- Solo procede en delitos flagrantes, sancionados con pena de hasta cinco años y los delitos contra la propiedad cuyo monto no exceda de treinta salarios básicos unificados

- La o él juez de garantías penales es quien resolverá la causa mediante sentencia condenatoria o ratificadora de inocencia. 
En este momento puede encontrarse una gran diferencia; en razón de la capacidad de un solo juez para hallar una resolución sin que exista una contradicción por parte de otra persona que haya escuchado lo mismo que se expuso por las partes procesales.

A tal efecto, el Artículo 597 del mismo cuerpo legal determina las actividades investigativas de la instrucción fiscal, en la cual las partes podrán recabar los elementos necesarios de cargo y descargo para sustentar la investigación y la defensa de ser el caso, textualmente dispone:

Los sujetos procesales gozarán de libertad para obtener los elementos que sustentan sus alegaciones con sujeción a los principios del debido proceso, para lo cual podrán ejercer todas las actividades investigativas y utilizar los medios de prueba, con las restricciones establecidas en este Código. La persona procesada podrá presentar a la o al fiscal los elementos de descargo que considere convenientes para su defensa; así también la víctima podrá solicitar a la o al fiscal los actos procesales que considere necesarios para comprobar la existencia del delito. Si para obtenerlos se requiere de orden judicial, la o el fiscal la obtendrá de la o el juzgador (COIP, 2014)

Así mismo, los sujetos procesales según lo que determina el artículo 598 del cuerpo legal ya mencionado, pueden solicitar estas diligencias al fiscal que lleva la investigación dentro de los cuales se va a obtener los elementos de convicción que crean pertinentes.

Para esto es necesario tomar en cuenta quien es la persona procesada, para esto el artículo 440 del cuerpo legal expresado determina:

Se considera persona procesada a la persona natural o jurídica, contra la cual, la o el fiscal formule cargos. La persona procesada tendrá la potestad de ejercer todos los derechos que le reconoce la Constitución, los Instrumentos Internacionales de Derechos Humanos y este Código (COIP, 2014)

Tal como lo determina mencionado artículo, es sujeto de derecho toda persona que se encuentre procesada e investigada, a la cual se le deben respetar todos los derechos establecidos en la Constitución e Instrumentos Internacionales. 


\section{Derechos y garantías}

Es importante resaltar que frecuentemente se han confundido como sinónimos los términos derechos y garantías. Existe una clara diferenciación, pues mientras los primeros son aquellas facultades o valores esenciales que tiene cada persona, las garantías son aquellos mecanismos de protección con que cuenta una persona para hacer eficaz el ejercicio de un derecho (JUDITH, s.f.)

Al definir estos conceptos es posible percatarse, que al garantizar los derechos, estos mecanismos de protección sirven para poder impedir la violación de los mismos cuando estos han sido transgredidos a la persona.

De acuerdo a Arciniega (2011), son mecanismos o herramientas que la Constitución concede a las personas, colectivos, pueblos, nacionalidades y a la naturaleza, con la finalidad de: Prevenir la vulneración de sus derechos.

Asimismo, la Constitución de la República del Ecuador establece mecanismos de aplicación de los derechos y garantías a todas las personas, sin determinación alguna o discriminación.

Por ello, al hablar de las garantías constitucionales, se hace referencia a diferentes tipos de garantías, como las: normativas, políticas públicas, institucionales y jurisdiccionales.

En este caso particular, la parte que compete es la garantía de carácter normativo. Esto en razón de que son aquellos mecanismos en los cuales lo principal es garantizar que el carácter normativo de la Constitución se vincule a las demás leyes, las cuales deben de estar a disposición de lo emanado por la carta magna; de esta manera, los derechos no se ven limitados para nadie.

Es así que la Constitución de la República del Ecuador establece que:

Artículo 84. La Asamblea Nacional y todo órgano con potestad normativa tendrá la obligación de adecuar, formal y materialmente, las leyes y demás normas jurídicas a los derechos previstos en la Constitución y los tratados 
internacionales, y los que sean necesarios para garantizar la dignidad del ser humano o de las comunidades, pueblos y nacionalidades. En ningún caso, la reforma de la Constitución, las leyes, otras normas jurídicas ni los actos del poder público atentarán contra los derechos que reconoce la Constitución

De alli que, ninguna reforma hecha a las diferentes partes de la normativa nacional deben ir en contra de los preceptos constitucionales, más aun si con estas reformas se produciría la violación de derechos que se encuentran nacional y universalmente garantizados.

\section{Suspensión condicional de la pena}

Existe todo un párrafo la tratar el tema de la suspensión condicional de la pena, luego de haberse sentenciado a la persona como culpable del cometimiento de una infracción penal.

A tal efecto, el COIP determina las formalidades para la suspensión de la pena impuesta en primera instancia, una vez que la parte solicitante en la audiencia de juicio o las veinticuatro horas posteriores a esta, cumpla con los requisitos determinados para proceder con el otorgamiento de este beneficio.

Artículo 630.- Suspensión condicional de la pena.- La ejecución de la pena privativa de libertad impuesta en sentencia de primera instancia, se podrá suspender a petición de parte en la misma audiencia de juicio o dentro de las veinticuatro horas posteriores, siempre que concurran los siguientes requisitos:

1. Que la pena privativa de libertad prevista para la conducta no exceda de cinco años.

2. Que la persona sentenciada no tenga vigente otra sentencia o proceso en curso ni haya sido beneficiada por una salida alternativa en otra causa.

3. Que los antecedentes personales, sociales y familiares del sentenciado, así como la modalidad y gravedad de la conducta sean indicativos de que no existe necesidad de la ejecución de la pena. 
4. No procederá en los casos de delitos contra la integridad sexual y reproductiva, violencia contra la mujer o miembros del núcleo familiar.

La o el juzgador señalará día y hora para una audiencia con intervención de la o el fiscal, el sentenciado, la o el defensor público o privado y la víctima de ser el caso, en la cual se establecerán las condiciones y forma de cumplimiento durante el período que dure la suspensión condicional de la pena

Luego de esto, la persona sentenciada debe de cumplir las condiciones impuestas por la autoridad.

Artículo 631.- Condiciones.- La persona sentenciada durante el período que dure la suspensión condicional de la pena cumplirá con las siguientes condiciones:

1. Residir en un lugar o domicilio determinado e informar cualquier cambio del mismo a la autoridad competente que establezca la o el juzgador.

2. Abstenerse de frecuentar determinados lugares o personas.

3. No salir del país sin previa autorización de la o el juez de garantías penitenciarias.

4. Someterse a un tratamiento médico, psicológico o de otra naturaleza.

5. Tener o ejercer un trabajo, profesión, oficio, empleo o voluntariamente realizar trabajos comunitarios.

6. Asistir a algún programa educativo o de capacitación.

7. Reparar los daños o pagar una determinada suma a la víctima a título de reparación integral o garantizar debidamente su pago.

8. Presentarse periódicamente ante la autoridad designada por la o el juzgador y en su caso, acreditar el cumplimiento de las condiciones impuestas.

9. No ser reincidente.

10. No tener instrucción fiscal por nuevo delito. 


\section{Principio de celeridad}

El principio de celeridad debe conciliar, primero, la oportunidad de la administración de justicia para conocer las peticiones formuladas, la procedencia de la vía procesal escogida y la pertinencia de las pruebas para una decisión justa $\mathrm{y}$, segundo, el interés de las partes o de los sujetos procesales, para que sus reclamaciones o recursos se decidan con rapidez. (Montoya, s.f.)

En este sentido, la administración de justicia es uno de los pilares fundamentales para el resarcimiento de una sociedad y tranquilidad jurídica. La vía legal debe en lo principal tratar la equidad entre las partes y que el fin de un litigio jurídico sea los más rápido y viable para evitar un congestionamiento de causas.

El Dr. Niklas Luhmann citado por Oscar Santiago Tibán Cajamarca expresa que: La celeridad procesal está vinculada, antes de todo, a la esencia de los derechos humanos. Esto porque la vida humana es breve y los conflictos sociales deben ser solucionados lo más temprano posible para que el Derecho cumpla su función de estabilizador de expectativas individuales y colectivas. (Cajamarca, 2013)

De esta manera se configura que entre más rápido se encuentre la solución a los conflictos jurídicos, más rápido es el resarcimiento tanto de la víctima como la aplicación de la pena a una persona privada de su libertad, ya que mientras no obtenga un resultado sobre el cometimiento de un hecho delictivo, no tendrá estabilidad de si debe estar más tiempo en un centro de privación de libertad o se confirma su inocencia.

La Constitución de la República del Ecuador en su artículo 75 establece que sin distinción alguna, todas las personas tienen acceso a la justicia y dentro de sus principales intereses esta, acceder a la justicia con celeridad, y el incumplimiento de esta disposición causa sanción por el retardo injustificado de la misma. 
Artículo. 75.- Toda persona tiene derecho al acceso gratuito a la justicia y a la tutela efectiva, imparcial y expedita de sus derechos e intereses, con sujeción a los principios de inmediación y celeridad; en ningún caso quedará en indefensión. El incumplimiento de las resoluciones judiciales será sancionado por la ley. (El subrayado es nuestro)

Así mismo el principal artículo sobre la celeridad procesal, se concentra en el artículo 169, en el cual se consagra como principio para la realización de la justicia, en la cual se debe de velar el debido proceso, garantizando los derechos de todos los ciudadanos.

Artículo. 169.-EI sistema procesal es un medio para la realización de la justicia.

Las normas procesales consagrarán los principios de simplificación, uniformidad, eficacia, inmediación, celeridad y economía procesal, y harán efectivas las garantías del debido proceso. No se sacrificará la justicia por la sola omisión de formalidades (CRE, 2008)

De igual forma, el Código Orgánico de la Función Judicial (COFJ) también plasma la celeridad en la justicia procesal, en los siguientes artículos:

Art. 18.- SISTEMA-MEDIO DE ADMINISTRACION DE JUSTICIA.- El sistema procesal es un medio para la realización de la justicia. Las normas procesales consagrarán los principios de simplificación, uniformidad, eficacia, inmediación, oralidad, dispositivo, celeridad y economía procesal, y harán efectivas las garantías del debido proceso. No se sacrificará la justicia por la sola omisión de formalidades.

\section{Art. 19.- PRINCIPIOS DISPOSITIVO, DE INMEDIACION Y} CONCENTRACION.- Todo proceso judicial se promueve por iniciativa de parte legitimada. Las juezas y jueces resolverán de conformidad con lo fijado por las partes como objeto del proceso y en mérito de las pruebas pedidas, ordenadas y actuadas de conformidad con la ley. Sin embargo, en los procesos que versen sobre garantías jurisdiccionales, en caso de constatarse la vulneración de derechos que no fuera expresamente invocada por los 
afectados, las juezas y jueces podrán pronunciarse sobre tal cuestión en la resolución que expidieren, sin que pueda acusarse al fallo de incongruencia por este motivo. Los procesos se sustanciarán con la intervención directa de las juezas y jueces que conozcan de la causa. Se propenderá a reunir la $\underline{\text { actividad procesal en la menor cantidad posible de actos, para lograr la }}$ concentración que contribuya a la celeridad del proceso.

Art. 20.- PRINCIPIO DE CELERIDAD.- La administración de justicia será rápida y oportuna, tanto en la tramitación y resolución de la causa, como en la ejecución de lo decidido. Por lo tanto, en todas las materias, una vez iniciado un proceso, las juezas y jueces están obligados a proseguir el trámite dentro de los términos legales, sin esperar petición de parte, salvo los casos en que la ley disponga lo contrario. El retardo injustificado en la administración de justicia, imputable a las juezas, jueces y demás servidoras y servidores de la Función Judicial y auxiliares de la justicia, será sancionado de conformidad con la ley (El subrayado es nuestro)

\section{Materiales y Métodos}

Se realiza una investigación bibliográfica, científico jurídica. En virtud de lo expuesto se procede a examinar la doctrina, esencialmente en lo que respecta a las garantías constitucionales y el Código Orgánico Integral Penal en relación con el procedimiento directo. La información fue recopilada a través de entrevistas, fichas bibliográficas, fichas linkográficas y consultas por internet, desplegándose con base a los principios jurídicos de celeridad, contradicción, igualdad de las partes, seguridad jurídica, oralidad e inmediación. Fueron entrevistados 50 abogados en libre ejercicio de la ciudad de Portoviejo, como informantes clave para este trabajo.

\section{Resultados}

Recopilados los datos por medio de las técnicas e instrumentos de recolección de información, se analizan en una matriz, que arroja los siguientes resultados:

El cien por ciento de las personas encuestadas conocen sobre el procedimiento directo, y como se aplica en la actualidad para los delitos que estipula el Código Orgánico Integral Penal, así como sus condiciones. Por otro lado, el setenta y dos por ciento de las personas expresaron que se vulnera el 
principio de inocencia en la aplicación del procedimiento directo mientras que el veintiocho por ciento creen que no se viola este principio. Una buena diferencia entre el pincipio de culpabilidad y principio de inocencia.

El setenta y seis por ciento señalan expresamente, que si se cumple con el principio de celeridad en la aplicación del procedimiento directo, pero un doce por ciento manifiesta que no considera que se adecue el principio.

Por otro lado, el noventa por ciento de los informantes clave consultados, expresan que los delitos de sustancias estupefacientes y psicotrópicas no deberian de ser tratados mediante procedimiento directo, mientras que el cinco por ciento opinan que si.

De igual forma, el veintiocho por ciento de las personas encuestadas expresan que el procedimiento directo si afecta el principio de defensa, mientras que el veintidos por ciento considera que no afecta en nada.

Finalmente, el ochenta por ciento de los encuestados señala que se deben ampliar los plazos estipulados para la sustanciación del procedimiento directo, mientras que el diez por ciento no creen necesario ampliar los plazos.

\section{Conclusiones}

Una vez obtenido los resultados producto del análisis realizado, se enuncian las conclusiones del trabajo:

En primer lugar, el procedimiento directo es una forma de recabar la justicia de una manera oportuna en un tiempo mucho más rápido, en el cual los operadores de justicia deben de aplicar su mayor esfuerzo por obtener un resultado eficaz al momento de dictar una sentencia.

Como segunda conclusión, la fiscalía no cuenta con los medios necesarios para la aplicación de este procedimiento alternativo, debido a que no se encuentran instaurados de manera absoluta la posesión de peritos exclusivos para este tipo de investigaciones.

En tercer lugar, el principio de celeridad procesal no debe de afectar el principio de defensa, ni tampoco puede dejar a la parte acusadora en este caso, para probar un hecho sin el tiempo y los medios 
necesarios para descubrir y plantear algo muy parecido a la reconstrucción de un hecho, en el que se vaya a sancionar a una persona por un ilícito, al igual reparar los daños de la víctima.

\section{Referencias Bibliográficas}

Alfonso, Z. P. (2013). Estudio introductorio al codigo organico integral penal. Referido al libro primero. Quito, Ecuador: Corporacion de estudios y publicaciones.

Arciniega, H. (Octubre de 2011). Biblioteca Corte Constitucional. Recuperado el 05 de Agosto de 2015, de http://www.google.com.ec/url?sa=t\&rct=j\&q=\&esrc=s\&source=web\&cd=3\&sqi=2\&ved=0C C0QFjACahUKEwjdyvSGrZLHAhUMIQ0KHYY_AIM\&url=http\%3A\%2F\%2Fbivicce.cort econstitucional.gob.ec\%2Fbases\%2Fbiblo\%2Ftexto\%2FCartilla_3_Garantias_constitucional es\%2FCartilla_3_Garantias

Constitución de la República del Ecuador (2008) Quito, Ecuador:Montecristi

Código Orgánico Integral Penal (2014) . Quito, Ecuador: Lexis.

Código Orgánico de la Función Judicial (2015) Quito, Ecuador: Lexis.

Cajamarca, O. S. (2013). Repositorio Universidad Técnica de Ambato. Recuperado el 06 de agosto de 2015, de http://repositorio.uta.edu.ec/jspui/handle/123456789/5267

Judith, S. M. (s.f.). Universidad Flacso. Recuperado el 05 de Agosto de 2015, de Garantías Constitucionales y derechos humanos de las mujeres: www.flacso.org.ec/docs/safismsalgado.pdf

Montoya Gallo, L. A. (s.f.). Departamento de Derecho Internacional, OEA. Recuperado el 06 de Agosto de 2015, de Resoluciones Asamblea General: http://www.oas.org/juridico/spanish/adjust25.htm 
